Portland State University

PDXScholar

$11-24-1981$

\title{
The Effect of Early Handling on the Sexually Dimorphic Rate of Extinction of a Conditioned Taste Aversion in Rats
}

Rebecca Lee Yoder

Portland State University

Follow this and additional works at: https://pdxscholar.library.pdx.edu/open_access_etds

Part of the Biological Psychology Commons

Let us know how access to this document benefits you.

Recommended Citation

Yoder, Rebecca Lee, "The Effect of Early Handling on the Sexually Dimorphic Rate of Extinction of a Conditioned Taste Aversion in Rats" (1981). Dissertations and Theses. Paper 3141.

https://doi.org/10.15760/etd.3132

This Thesis is brought to you for free and open access. It has been accepted for inclusion in Dissertations and Theses by an authorized administrator of PDXScholar. Please contact us if we can make this document more accessible: pdxscholar@pdx.edu. 
AN ABSTRACT OF THE THESIS OF Rebecca Lee Yoder for the Master of Science in Psychology presented November 24, 1981.

Title: The Effect of Early Handling on the Sexually Dimorphic Rate of Extinction of a Conditioned Taste Aversion in Rats.

APPROVED BY THE MEMBERS OF THE THESIS COMMITTEE:

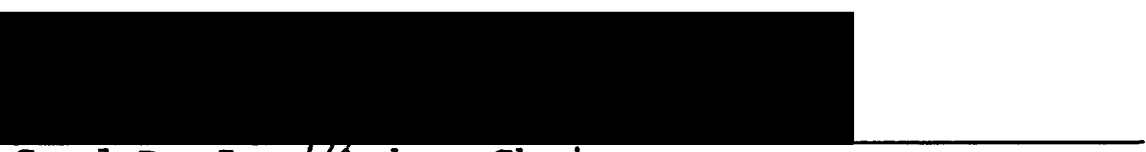

Cord B. Senqfitake, Chairman

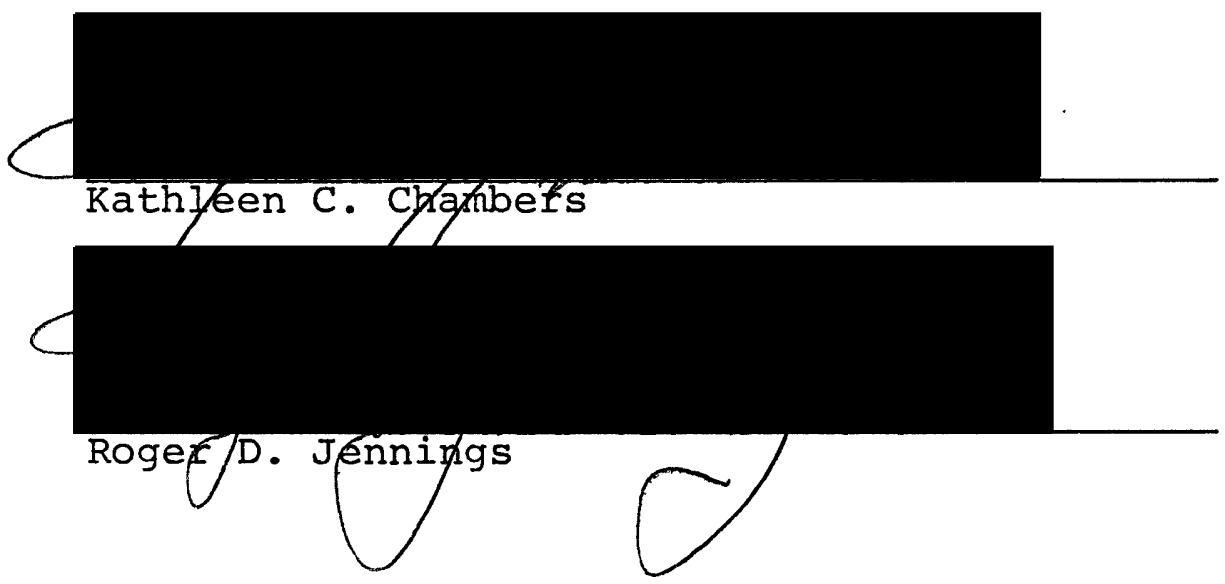

Male rats have been found to extinguish a conditioned taste aversion slower than females. It has also been found that female rats that have been "handled" (i.e., exposed to daily brief isolation from siblings and mother) during the preweaning period extinguish a taste aversion faster than nonhandled females. The present study sought to combine and extend these findings by testing handled and nonhandled females and males in a conditioned taste aversion under the 
methodological conditions used in the sex difference research.

At birth eight litters were culled to eight pups each with four females and four males per litter. Four litters were assigned to the handled and four to the nonhandled condition. Beginning the day after birth and culling, handled pups were taken from their nests and placed alone in separate tin cans for three minutes daily until day 21 (weaning). Nonhandled litters were undisturbed except for culling and weekly cage cleaning.

Between weaning and testing, same sex siblings were housed together and disturbed only for cage cleaning. When 100 days old, the animals were adapted to individual cages for one week and then given two hours access to a $10 \%$ sucrose solution followed by an injection of a $0.30 \mathrm{M}$ solution of $\mathrm{LiCl}(20 \mathrm{ml} / \mathrm{kg})$. Two days later, daily two hour extinction trials were initiated and then were continued six days a week until the animal had reached $100 \%$ of its day one consumption.

An analysis of variance indicated a significant sex difference within both the handled and nonhandled groups, which replicates the previous findings. However, there were no significant differences due to the handling conditions in the males or the females.

This failure to replicate the previously reported handling effect on rate of extinction in females is hypothe- 
sized to be due to procedural differences between the two studies. Four procedural differences that could account for the failure to find significant differences between handled and nonhandled females are outlined. These include differences in the degree of preconditioning familiarity with the $C S$, in the level of the US, in the time of testing and in the strain of rat. 
THE EFFECT OF EARLY HANDLING ON THE SEXUALIY DIMORPHIC RATE OF EXTINCTION OF A CONDITIONED TASTE AVERSION IN RATS

\title{
by
}

REBECCA LEE YODER

A thesis submitted in partial fulfillment of the requirements for the degree of

\author{
MASTER OF SCIENCE \\ in \\ PSYCHOLOGY
}

Portland State University 
TO THE OFFICE OF GRADUATE STUDIES AND RESEARCH:

The members of the Committee approve the thesis of Rebecca Lee Yoder presented November 24, 1981.

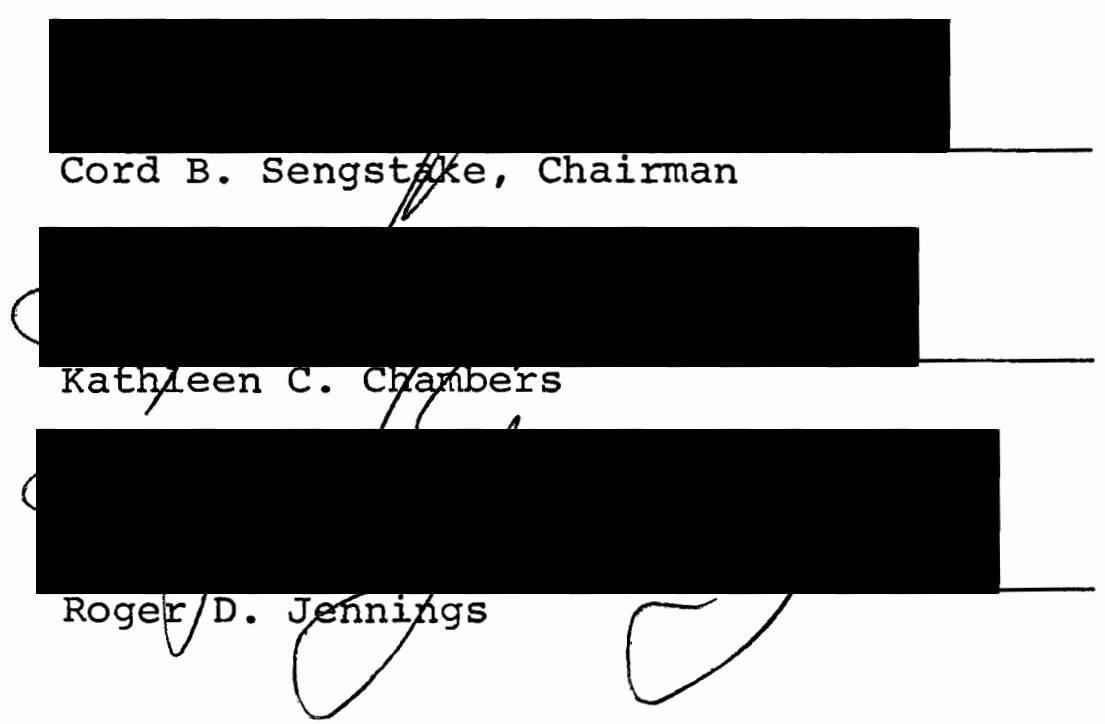

APPROVED :

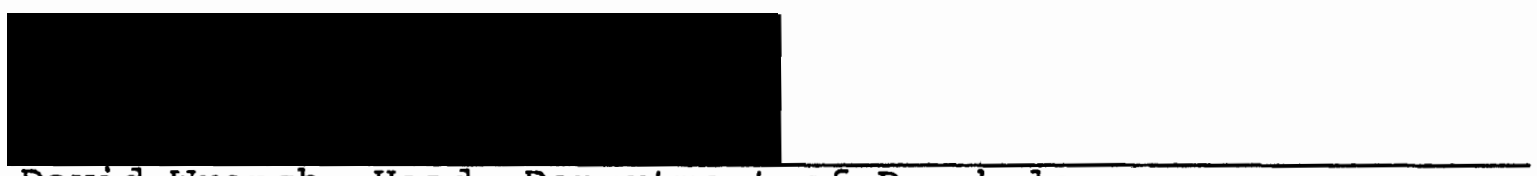

David Wrench, Head, Department of Psychology

Stanley E. Rauch, Dean of Graduate Studies and Research 
TABLE OF CONTENTS

PAGE

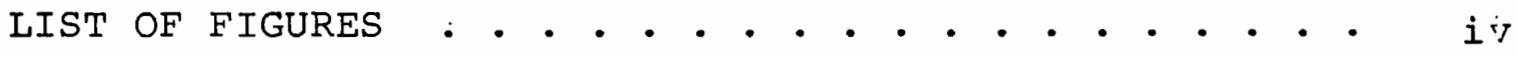
CHAPTER

I INTRODUCTION AND REVIEW OF THE LITERATURE • 1

II METHOD . • . . . . . . . . . . . 8

III RESULTS • • • • • • • • • • • • • • • • 11

IV DISCUSSION •. . . . . . . . . . . . . 12

REFERENCES •. • . . . . . . . . . . . . 20

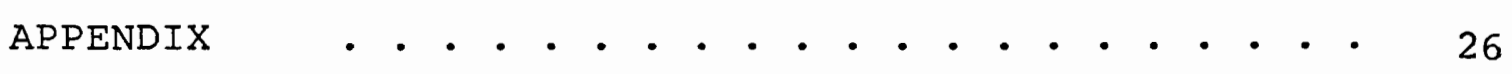




\section{LIST OF FIGURES}

FIGURE

PAGE

1. Mean Number of Days to Extinction . • • • • • 26 
INTRODUCTION AND REVIEW OF THE LITERATURE

The environment in which an organism exists was once thought to be comparable to a stage on which that creature acted out its genetically written script. Environment is now seen as a dynamic force which interacts with the psychobiological processes of a living creature at each point in its development. This interaction of creature and environment constitutes an experience, and the way in which that experience influences the subsequent growth and development of the organism has been a central concern of psychologists for some time. Sigmund Freud was one of the early theorists who recognized the role of experience in developing personality and behavior; on the basis of his clinical observations, he emphasized the importance of early or infantile experience and its influence on adult behavior.

One of the early lines of experimental investigation of the way in which early experience affects the adult behavior of nonhumans was prompted by a paper by Bernstein (1952). He reported that rats that had been held by an experimenter a few minutes a day from the time they were weaned until they were adults performed better in a maze than rats which had not been handled until they were adults. Since that time this phenomenon has been explored in great detail. Experimental manipulations of young animals have 
mortalities are found among handled animals than among nonhandled following 120 hours of food and water deprivation (Denenberg and Karas, 1959; 1961; Levine and Otis, 1958). However, contrary to the general rule, Levine and Cohen (1959) found that animals stimulated in the postnatal period have a decreased resistance to leukemia virus.

Finally, a physiological parameter which has received much attention in the investigation of the effects of postnatal handling is the level of plasma corticosterone, the major hormone secreted by the adrenal cortex of the rat. Corticosterone is released whenever the animal is encountering novel or noxious stimuli. Generally, plasma corticosterone levels are less elevated in handled as compared to nonhandled animals following exposure to novel stimuli (Levine, 1962b; Ader, 1968; 1970).

Behaviorally, animals manipulated in infancy have been reported to be sexually precocious (Morton, Denenberg and Zarrow, 1963), to learn faster and make fewer errors on some avoidance learning tasks (Denenberg and Karas, 1960; Levine, 1956), to be less emotional, i.e., to show less defecation and more ambulation in an open field test, and to show less vocalization and respond better to human handling (Denenberg, 1967). Handled animals also have been reported to be more aggressive (Levine, 1959) and to be more exploratory (Deneberg and Grota, 1964). The more complex the environment, the more handled animals explore; while in nonhandled animals, 
the response to increased complexity is the opposite (DeNelsky and Denenberg, 1967).

Recently Weinberg, Smotherman and Levine (1978) have found that early handling also affects responses in a conditioned taste aversion. A conditioned taste aversion is the avoidance of a novel food after a taste of that food has been followed by illness (Rzóska, 1953). If repeated contact with the taste is allowed without further illness, rats eventually will extinguish this conditioned food aversion (Garcia, Kimeldorf and Koelling, 1955). In the Weinberg et al. (1978) study, they found that handling reduces the magnitude of the initial aversion and increases the rate of extinction in female rats.

It would be of interest for a number of reasons to know the influence of this early treatment on a male's behavior in a conditioned taste aversion as well. First, males and females are affected differentially by handling on other measures. There are sex differences in exploration in a hole-board (Weinberg, Krahn and Levine, 1978). This apparatus is a wooden box with four equally spaced holes in the floor. Objects can be placed in the holes and this allows for a measure of exploration based on number and duration of head-dips into the holes rather than on ambulation. Females head-dip for longer durations than males when objects are present, and the duration of head-dips does not decrease over days as it does for males. When no objects are present 
in the holes, handled females head-dip more than nonhandleds. But, as stimulus variation increases, the nonhandled females explore as much as those handled. The males respond in an opposite manner. With low stimulus variation, handled and nonhandled males do not differ; but with an increase in stimulus variation, handled males explore more.

Weinberg and Levine (1977) have shown that the corticosterone response of males and females differs during an active avoidance task in a two-way shuttle box. Over the course of avoidance training all females show a decrease in corticosterone levels whether given low or high shock. the corticosterone levels of handled females consistently are lower than those of nonhandled. The handled and nonhandled males show a decrease in corticosterone at low shock intensity but only the handled group shows this adaptation at high shock intensity.

Finally, Erskine, Stern and Levine (1975) have found sex differences in the effect of handling on shock induced fighting and ACTH levels in males and females. It has been shown that males paired in a shock situation and allowed to fight have lower plasma ACTH levels than males shocked alone in the test chamber (Conner, Vernikos and Levine, 1971). When testing handled and nonhandled males and females in paired or unpaired shock situations, Erskine, et al. (1975) found higher АCTH levels in shocked alone handled females and handled males. However, the plasma ACTH levels of the 
nonhandled males in the shocked alone condition did not differ from those in the paired shocked condition whereas the nonhandled females in the shocked alone condition had higher ACTH levels than those in the paired shock condition. (Erskine et al. suggested that their results and those of Conner et al. (1971) are compatible since the history of the subjects in the Conner study was closer to that of handled than nonhandled animals.) Handling in this case has no influence on the response of the female but it does affect the male and eliminates the sex difference which is seen in nonhandled animals.

A second reason for looking at the effect of handling on the behavior of both males and females in a conditioned taste aversion lies in the fact that there are sex differences in the adrenocortical response of the rat (see Gray, 1971, for a review). In adults, the adrenals are larger in females than in males, and resting levels of both plasma and adrenal corticosterone also are higher in females. The corticosteroid response to stress initially is higher in females but it returns more rapidly to a prestress level. This is of interest since one of the consistently observed consequences of early handling is an attenuation of the animal's subsequent adrenocortical response to environmental events (Ader, 1975). In addition, pituitary-adrenal hormones are involved in conditioned taste aversions. Hennessey, Smotherman and Levine (1976) and Rigter and Popping 
(1976) have found that injection of ACTH during extinction prolongs the aversion. If dexamethasone (a synthetic glucocorticoid which blocks ACTH release) is administered before the toxin, the aversion is attenuated.

Finally, there is a sex difference in the rate of extinction of a conditioned taste aversion in nonhandled animals (Chambers and Sengstake, 1976). Under ad lib food and water conditions males extinguish more slowly than females.

The present study therefore was undertaken to. see if early handling would influence differentially the rate of extinction of males and females. 
CHAPTER II

METHOD

The subjects in this study were 64 Sprague-Dawleyderived rats bred in the psychology laboratory at Portland State University. The eight mothers of these animals were housed individually in $18 \times 9 \times 8$ inch boxes and kept on a 12:12 hour light/dark cycle. When the pups were born the litters were culled to eight, with four females and four males in each litter. If the litter size was less than eight, foster pups were assigned to achieve the desired litter size and sex ratios. Whenever possible, however, pups were left with their real mothers. Four litters were assigned randomly to the handled condition and four to the nonhandled condition, thereby producing four experimental groups: handled females; handled males; nonhandled females; and nonhandled males.

The day after birth and culling the manipulation of the handled animals began. For each of the four handled litters, the mother was placed in a holding cage while all her pups were removed from the nest and placed alone for three minutes in separate 46-ounce tin cans containing a thin layer of wood shavings. The pups were returned to their nest following this procedure and then their mother was returned. This manipulation continued daily until the pups were weaned at 21 days of age. Meanwhile, the non- 
handled litters remained undisturbed during the nursing period except for initial culling and cage cleaning once a week. Cage cleaning consisted of momentary transport en masse to a fresh box. This minimal amount of handling was considered preferable and less stressful to the animal than a foul cage.

Following weaning, siblings of the same sex were housed together until they were tested. Except for weekly cage cleaning all animals were undisturbed during the postweaning, pre-testing interval. Throughout the experiment the animals were kept on a 12:12 hour light/dark cycle and were given ad libitum access to food and water except during the test period when their water was removed.

When the rats were 100 to 120 days of age, they were rehoused in individual testing cages and habituated to the testing regimen. Each day at the beginning of the dark portion of the light/dark cycle their water bottles were replaced for two hours by graduated cylinders of chilled tap water. Seven days later, acquisition of the conditioned taste aversion was induced. The water bottles were removed and instead of chilled tap water, the rats were given access to graduated cylinders of a chilled $10 \%$ sucrose solution $(w / v$ in water) during the two hour test period. Sucrose level was recorded at the beginning and the end of the two hours and individual consumption was computed. Each animal then was taken from its home testing cage, weighed and given 
an injection (i.p.) of a $0.30 \mathrm{M}$ solution of lithium chloride in the amount of $20 \mathrm{ml} / \mathrm{kg}$ body weight. Following the injection, the animal was placed back in its cage and the water bottle was returned.

The animals were left undisturbed for two days. After this time extinction trials began. These trials occurred six days a week and consisted of removing the water bottles and giving the rats access to the sucrose solution during the two hour test period. The rats were not handled during these extinction trials. Consumption was recorded daily and each animal was tested until it had regained its acquisition day consumption level. 


\section{RESULTS}

The extinction scores (the number of days it took an animal to reach $100 \%$ of its acquisition day consumption) were analyzed using a three factor (handling condition $x$ litter $\mathrm{x}$ sex) analysis of variance in which the second factor (Iitters) is nested under the first (Winer, 1962). A significant difference in extinction rates due to sex was obtained, $F(1,45)=27.55, \underline{p}<.001$, the females extinguished faster than the males (see figure 1). There were, however, no significant differences due to handling, $F(1,45)=3.09$, nor was there a handling condition $\mathrm{x}$ sex interaction, $F(1,45)=.03$. Finally, there were no significant differences due to litters, $F(6,45)=1.45$.

The amount of sucrose consumed on acquisition day was analyzed with a two factor (handling condition $\mathrm{x}$ sex) analysis of variance to determine differences in neophobia. There were no significant differences due to $\operatorname{sex}, F(1,56)=$ .904 , or handling, $F(1,56)=.822$, and there was no interaction between these two factors, $F(1,56)=2.466$. 
The sex difference in rate of extinction from a conditioned taste aversion, previously reported by Chambers and Sengstake (1976), was replicated. Females resumed consumption of the aversive substance sooner than males. Early handling, however, had no influence on rate of extinction in either sex. Thus, the finding of Weinberg, Smotherman and Levine (1978), that early early handling accelerates extinction in the female was not replicated.

The failure to replicate the effects of handing could be accounted for by at least two factors. First, it may be due to a type II error. This is not likely, however, since sample sizes in the present study were twice as large $(n=16)$ as those in the Weinberg, et al. (1978) study and since there was a tendency toward longer rather than shorter extinction in the handled groups (see figure 1).

A second possible reason for the difference in findings is that the procedures of the two studies differed. The paradigm used in the present study was the same as that used by Chambers and Sengstake (1976), and it differs in a number of ways from that used by Weinberg et al. (1978). I suggest that some aspect(s) of the procedural differences in the present investigation effectively blocked any manifestation of differences resulting from early experience. 
One possibly important difference is the degree of familiarity with the conditioned stimulus experienced by the animals in the two studies. Weinberg, et al. used a $30 \mathrm{~min}-$ ute test and four days of pre-exposure before the conditioned exposure, while animals in the present investigation had a single two hour exposure before conditioning. It is well established that increasing the number of prior exposures to a substance increases the difficulty in conditioning an animal to avoid that substance (Best, 1975; Elkins, 1973; Nachman and Jones, 1974). Elkins (1973) systematically investigated the way in which familiarity influences aversion formation. Looking at five pre-exposure periods ranging from zero to twenty days he found that preconditioning familiarity is inversely related to the strength of the resultant aversion. One day of pre-exposure failed to attenuate the initial aversion but it did accelerate extinction. The formation of an aversion was blocked completely by 20 days of pre-exposure to the CS while orderly and graded degrees of aversion formation resulted from intermediate preexposures.

Kalat and Rozin (1973) have suggested that in a conditioned taste aversion two learning processes are possible. Learning takes place in the delay period between the presentation of the CS and the US. When consumption and poisoning are close in time, the rat learns to avoid the taste. But, as the CS-US interval becomes greater, i.e., as the absence 
of aversive stimuli is prolonged, the animal learns safety. Under the conditions of the present study, where the animal's initial exposure to the $\mathrm{CS}$ is followed immediately by toxicosis, there is acute evidence that the novel sucrose is harmful and essentially no evidence that it is not. In the Weinberg study subjects had four half-hour exposures separated by 24 hour intervals before the conditioned exposure. Those animals had a lot of information indicating that the substance was safe. It may be that handling enhances the learning of safety, as in the Weinberg study, but has no effect on the learning of an aversion to a taste, as in the present investigation.

Data from pilot research in our lab where all of the conditions of the present study were kept the same, except that animals were tested under zero or four half-hour preexposures prior to conditioning, indicate no significant differences due to handling procedure for either exposure condition. These preliminary data suggest that at least number of exposures alone cannot account for the lack of replicability.

Another important procedural difference between the two studies is the dosage level of the toxin. The dose used by Weinberg et al. was $7.5 \mathrm{ml} / \mathrm{kg}$ of a $0.40 \mathrm{M}$ solution of LiCl. In the present study animals received $20 \mathrm{ml} / \mathrm{kg}$ of a $0.30 \mathrm{M}$ solution. In both studies the toxin was injected intraperitoneally. According to a study by Nachman and Ashe 
(1973) it is the total amount of LiCl and not the specific volume or concentration that is responsible for the strength of a produced aversion. Total amount can be measured in molar equivalencies per kilogram (mEq/ $\mathrm{kg}$ ) and is found by multiplying toxin concentration by injected volume. By varying these two parameters, Nachman and Ashe (1973) generated a dose response curve and found that $0.15 \mathrm{mEq} / \mathrm{kg}$ was the threshold dose for producing an aversion and that $3.0 \mathrm{mEq} / \mathrm{kg}$ was sufficient to produce a strong aversion. It should be noted that this dose was sufficient for animals that were water deprived and in a forced extinction situation where the aversive sucrose was the only available liquid during testing. Weinberg, et al. rats received $3.0 \mathrm{mEq} / \mathrm{kg}$ while the present animals received $6.0 \mathrm{mEq} / \mathrm{kg}$, or twice the quantity of Licl used by Weinberg and known to cause strong aver sions in deprived rats.

It is reported that in acute situations handled animals appear to be more sensitive to their environments than nonhandled. Manipulated animals exhibit a significantly greater depletion of adrenal ascorbic acid after 90 minutes of exposure to cold than do nonmanipulated controls (Levine, Alpert and Lewis, 1958). In a further study, Levine (1962b) has found that manipulated animals have a more vigorous physiological response to acute footshock than do control animals as measured by the amount of circulating corticosterone in the blood up to 15 minutes after the termination of 
shock. In another investigation Haltmeyer, Denenberg and Zarrow (1967) found that handled animals respond more readily to shock, as measured by corticosterone levels, but also show a greater decrease in rate of response after shock termination. The relatively high dose of toxin used in the present study may constitute a situation sufficiently acute to make the handled animals respond more vigorously and acquire stronger aversions than they would at lower stimulus levels, e.g., those used in the Weinberg study.

A third procedural difference which may be important is the time of testing. There is a circadian rhythm in ACTH output, with highest levels occurring at the beginning of the active portion of the day and lowest levels during the resting portion of the day. In the nocturnal rat, the peak output of АСTH is at 4:00 p.m., and the nadir is at 4:00 a.m. (Smith, 1973). Weinberg et al. tested their animals within two and a half hours after the beginning of the light portion of the light/dark cycle when ACTH levels are naturally low, while in the present study animals were tested at the beginning of the dark period when ACTH levels are naturally high. Since ACTH and corticosterone are influential hormones in the acquisition and extinction of a conditioned taste aversion (Levine, Smotherman and Hennessey, 1977), the difference in test time may be important.

A final methodological factor which may have affected the outcome was the strain of animal used. Weinberg et al. 
used animals of a Long-Evans-Sprague-Dawley cross while the present study used Sprague-Dawley rats. Sprague-Dawley rats have been reported to be less responsive to handling than Long-Evans rats (Levine and Wetzel, 1963).

Early handling does not always influence an animal's physiological or behavioral response to environmental stimuli in a predictable way. With regard to adrenocortical reactivity, for instance, it has been demonstrated repeatedly that early handled animals have a reduced adrenocortical response relative to unmanipulated controls (see Ader, 1975, for a review). These findings are quite consistent with relatively innocuous stimuli. However, with more intense stimuli the results vary.

Ader (1970) has reviewed the literature on the susceptibility to somatic disease as a function of early handling and again the findings are inconsistent. Preweaning handling retards the growth of a transplanted tumor (Ader and Friedman, 1965) and increases resistance to gastric erosions (Ader, 1965). However, it decreases resistance to transplanted leukemia (Levine and Cohen, 1959) and has no effect on resistance to encephalomyocarditis virus or on the spontaneous development of leukemia in AKR mice (Friedman, Glasgow and Ader, 1969).

Findings on handling effects on learning have been difficult to piece together as well. For example, in three separate studies, where early handling conditions were almost 
identical, animals were trained as adults to avoid a .5 $\mathrm{mA}$ shock in a shuttle box. In one study, handled animals learned faster than controls (Levine and Wetzel, 1963); in another they learned more slowly (Ader, 1965); and, in a third study there were no differences in learning between handled and control subjects (Tapp and Markowitz, 1963). So, even though the major parameters (i.e., the type of early experience and the nature and intensity of environmental stimuli in the test situation) may be identical or very similar, it is clear that the factors which influence the behavioral expression are complex.

Both physiological and behavioral responses were examined in a study looking at the effects of early handling on the intake of novel substances (Weinberg, Smotherman and Levine, 1980). Half of the manipulated and control subjects were given a sucrose solution first and a saline solution second, while for the other half of the subjects the order of presentation was reversed. These researchers examined both consumption and plasma corticosterone levels following consumption. Under these conditions behavioral differences between handled and nonhandled animals are found with sucrose consumption while differences in plasma corticosterone levels are found following saline intake. Dissociations of behavioral and physiological results have been reported elsewhere as well (Weinberg and Levine, 1977). These findings indicate that the entire history of the 
organism, both the phylogenetic and the ontogenetic, is important in determining the effect of environmental stimili on early handled animals. A review of the literature on infantile experience indicates that the quality and quantity of early stimulation, the animal's age when stimulated, the particular independent and dependent variables in the test situation and the animal's experiences between initial stimulation and final testing are all important in determining the outcome of studies on infantile experience (Denenberg, 1967). In addition, they indicate that measurement of both behavioral and physiological responses may elucidate differences between handled and nonhandled animals that one type of measurement may not reveal.

In summary, it is likely that procedural factors in the present investigation obscured any significant differences between handled and nonhandled groups that have been demonstrated previously in a conditioned taste aversion. Whether the failure to find a difference between handled and nonhandled females is due to the degree of familiarity with the CS, the level of the US, the time of testing or the strain of rat remains to be determined. 


\section{REFERENCES}

Ader, R. 1965. "Effects of Early Experience and Differential Housing on Behavior and Susceptibility to Gastric Erosions in the Rat," Journal of Comparative and Physiological Psychology, 60:233-238.

Ader, R. 1968. "Effects of Early Experience on Emotional and Physiological Reactivity in the Rat," Journal of Comparative and Physiological Psychology, 66: 264-268.

Ader, R. 1970. "The Effect of Early Experience on the Adrenocortical Response to Different Magnitudes of Stimulation," Physiology and Behavior, 5: 837-839.

Ader, R. 1975. "Early Experience and Hormores: Emotional Behavior and Adrenocortical Function," In B. E. Eleftheriou and R. C. Sprott (Eds.) Hormonal Correlates of Behavior, Vol. 1., (New York: Plenum Press.), pp. 7-33.

Ader, R. and Friedman, S. B. 1965. "Differential Early Experience and Susceptibility to Transplanted Tumor in the Rat," Journal of Comparative and Physiological Psychology, 59: 361-364.

Bernstein, L. 1952. "A Note on Christie's 'Experimental Naivete and Experiential Naivete,' Psychological Bulletin, $49: 38-40$.

Best, M. R. 1975. "Conditioned and Latent Inhibition in Taste-Aversion Learning: Clarifying the Role of Learned Safety," Journal of Experimental Psychology: Animal Behavior Processes, 104: 97-113.

Chambers, K. C. and Sengstake, C. B. 1976. "Sexually Dimorphic Extinction of a Conditioned Taste Aversion in Rats," Animal Learning and Behavior, 4: 181-185.

Conner, R. L., Vernikus-Danellis, J. and Levine, S. 1971. "Stress, Fighting and Neuroendocrine Function," Nature, 234: 564-566.

DeNelsky, G. Y. and Denenberg, V. H. 1967. "Infantile Stimulation and Adult Exploratory Behavior: Effects of Handling Upon Tactual Variation Seeking," Journal of 
Comparative and Physiological Psychology, 63: 309-312.

Denenberg, V. H. 1967. "Stimulation in Infancy, Emotional Reactivity, and Exploratory Behavior," In: Neurophysiology and Emotion. D. C. Glass (Ed.), (New York: Rockefeller University Press and Russel Sage Foundation), pp. 161-190.

Denenberg, V. H. and Grota, L. J. 1964. "Social-Seeking and Novelty-Seeking Behavior as a Function of Differential Rearing Histories," J.Abn. Soc. Psychol., 69: 453456 .

Denenberg, V. H. and Karas, G. G. 1959. "Effects of Differential Infantile Handling Upon Weight Gain and Mortality in the Rat and Mouse," Science, 130: 629-630.

Denenberg, V. H. and Karas, G. G. 1960. "Interactive Effects of Age and Duration of Infantile Experience on Adult Learning," Psychological Reports, 7: 313-322.

Denenberg, V. H. and Karas, G. G. 1961. "Interactive Effects of Infantile and Adult Experience Upon Weight Gain and Mortality in the Rat," Journal of Comparative and Physiological Psychology, 54:170-174.

Elkins, R. L. 1973. "Attenuation of Drug-Induced Bait Shyness to a Palatable Solution as an Increasing Function of its Availability Prior to Conditioning," Behavioral Biology, 9: 221-226.

Erskine, M. S., Stern, J. M. and Levine, S. 1975. "Effects of Prepubertal Handling on Shock-Induced Fighting and ACTH in Male and Female Rats," Physiology and Behavior, $14: 413-420$.

Friedman, S. B., Glasgow, I. A. and Ader, R. 1969. "Psychosocial Factors Modifying Host Resistance to Experimental Infections," Annals of the New York Academy of Science, 164: 381-393.

Garcia, J., Kimeldorf, D. J. and Koelling, R. A. 1955. "Conditioned Aversion to Saccharin Resulting from Exposure to Gamma Irradiation," Science, 122: 157-158.

Gray, J. A. 1971. "Sex Differences in Emotional Behavior in Mammals Including Man: Endocrine Bases," Acta Psychologica, 35: 29-46.

Haltmeyer, G. C., Denenberg, V. H. and Zarrow, M. X. 1967. "Modification of the Plasma Corticosterone Response as 
a Function of Infantile Stimulation and Electric Shock Parameters," Physiology and Behavior, 2: 61-63.

Hennessey, J. W., Smotherman, W. P. and Levine, S. 1976.

"Conditioned Taste Aversion and the Pituitary-Adrenal

system," Behavioral Biology, 16: 413-424.

Kalat, J. W. and Rozin, P. 1973. "'Learned Safety' as a Mechanism in Long-Delay Taste Aversion Learning in Rats," Journal of Comparative and Physiological Psychology, 83: 198-207.

Levine, S. 1956. "A further Study of Infantile Handling and Adult Avoidance Learning," Journal of Personality, 25: 70-80.

Levine, S. 1957. "Infantile Experience and Resistance to Physiological Stress," Science, 126: 405.

Levine, S. 1959. "Emotionality and Aggressive Behavior in the Mouse as a Function of Infantile Experience," J. Genet. Psychol., 94 : 77-83.

Levine, S. 1962a. "The Psychophysiological Effects of Infantile Stimulation," In: E. Bliss (Ed.), Roots of

Behavior, (New York: Harper), pp. 246-253.

Levine, S. 1962b. "Plasma-Free Corticosteroid Response to Electric Shock in Rats Stimulated in Infancy," Science, 135: 795-796.

Levine, S. and Alpert, M. 1959. "Differential Maturation of the Central Nervous System as a Function of Early Experience," A. M. A. Arch. Gen. Psychiat., 1: 403405 .

Levine, S., Alpert, M. and Lewis, G. W. 1958. "Differential Maturation of an Adrenal Response to Cold Stress in Rats Manipulated in Infancy," Journal of Comparative and Physiological Psychology, 51: 774-777.

Levine, S. and Cohen, C. 1959. "Differential Survival to Leukemia as a Function of Infantile stimulation in DBA/ 2 Mice," Procedings of the Society for Experimental Biology and Medicine, 102: 53-54.

Levine, S., Smotherman, W. P. and Hennessey, J. W. 1977. "Pituitary-Adrenal Hormones and Learned Taste Aversion," In: Neuropeptide Influences on the Brain and Behavior, L. H. Miller, C. A. and Sandman and A. J. Kastin 
(eds.), (New York: Raven Press).

Levine, S. and Otis, L. 1958. "The Effects of Handling Before and After Weaning on the Resistance of Albino Rats to Later Deprivation," Canadian Journal of Psychology, 12: 103-108.

Levine, S. and Wetzel, A. 1963. "Infantile Experience, Strain Differences and Avoidance Learning," Journal of Comparative and Physiological Psychology, $56:$ 879-881.

Morton, J. R. C., Denenberg, V. H. and Zarrow, M. X. 1963. "Modification of Sexual Development through Stimulation in Infancy," Endocrinology, 72: 439-442.

Nachman, M. and Ashe, J. H. 1973. "Learned Taste Aversions in Rats as a Function of Dosage, Concentration and Route of Administration of LiCl," Physiology and Behavior, 10: 73-78.

Nachman, M. and Jones, D. R. 1974. "Learned Taste Aversions Over Long Delays in Rats: The Role of Learned Safety," Journal of Comparative and Physiological Psychology, 86: $949-956$.

Rigter, H. and Popping, A. 1976. "Hormonal Influences on the Extinction of Conditioned Taste Aversion," Psychopharmacologica, 46: 255-261.

Rzoska, J. 1953: "Bait Shyness, a Study in Rat Behavior," British Journal of Animal Behavior, 1: 128-135.

Smith, G. P. 1973. "Adrenal Hormones and Emotional Behavior," Progress in Physiological Psychology, Vol. 5.

Tapp, J. T. and Markowitz, H. 1963. "Infant Handling: Effects on Avoidance Learning, Brain Weight and Cholinesterase Activity," Science, 140: 486-487.

Weinberg, J., Krahn, E. A. and Levine, S. 1978. "Differential Effects of Handling on Exploration in Male and Female Rats," Developmental Psychobiology, 11: 251259 .

Weinberg, J. and Levine, S. 1977. "Early Handling Influences on Behavior and Physiological Responses During Active Avoidance," Developmental Psychobiology, 10: 161-169.

Weinberg, J., Smotherman, W. P. and Levine, S. 1978. "Early 
APPENDIX 


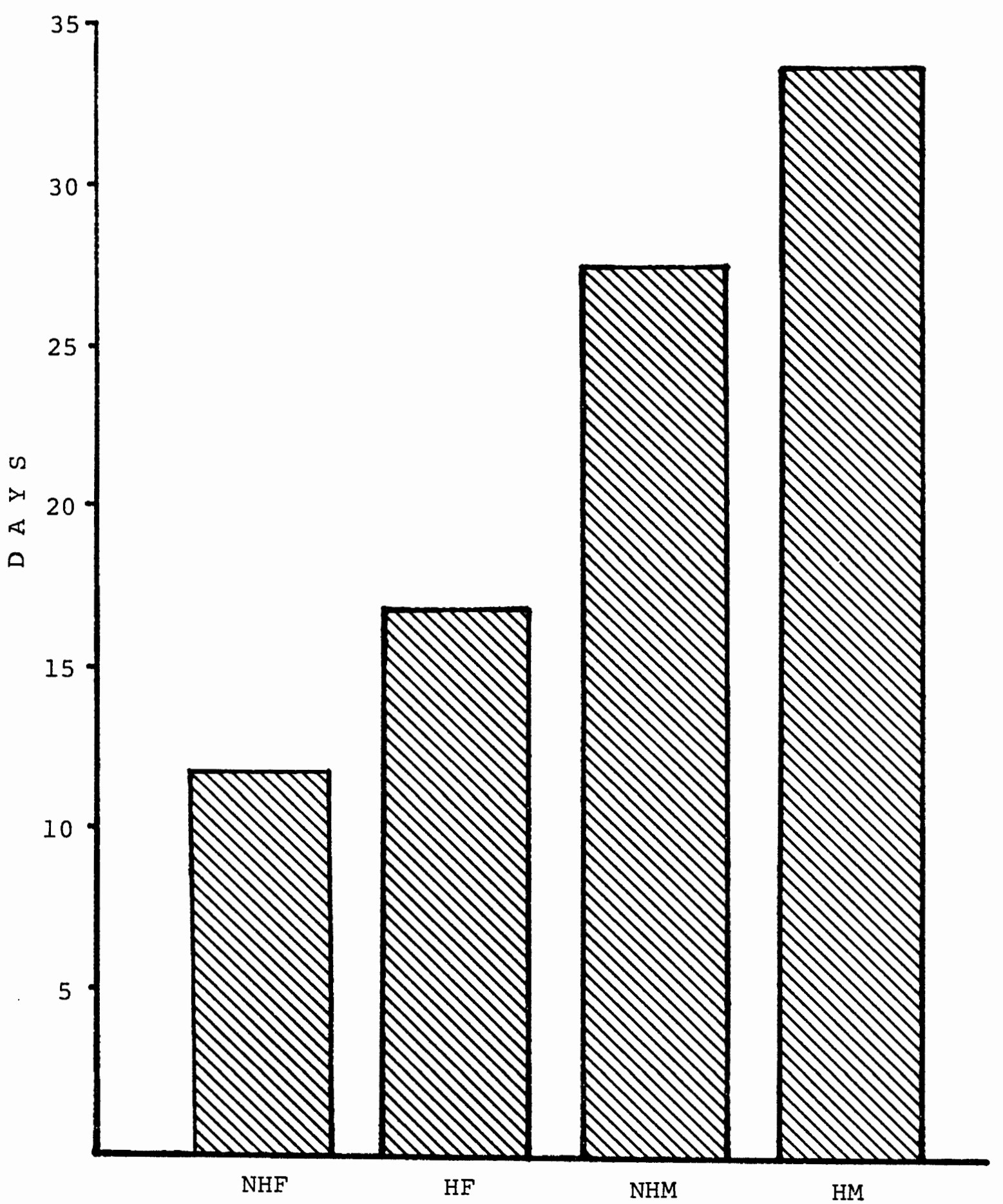

FIGURE I Mean number of days the nonhandled females (NHF), the handled females ( $\mathrm{HF}$ ), the nonhandled males (NHM) and the handled males (HM) drank less than $100 \%$ of their acquisition day consumption. 